\title{
Mosquito Behavior and Vertebrate Microbiota Interaction: Implications for Pathogen Transmission
}

\author{
María José Ruiz-López* \\ Departamento de Humedales, Estación Biológica de Doñana, Consejo Superior de Investigaciones Científicas, Sevilla, Spain
}

\section{OPEN ACCESS}

Edited by: Jenny C. Dunn,

University of Lincoln, United Kingdom

Reviewed by:

David Sungin Kang,

Cornell University, United States

Nsa Dada,

Norwegian University of Life

Sciences, Norway

Doug Brackney,

Connecticut Agricultural Experiment

Station, United States

*Correspondence:

María José Ruiz-López

mjruiz@ebd.csic.es

Specialty section:

This article was submitted to

Infectious Diseases,

a section of the journal

Frontiers in Microbiology

Received: 16 June 2020 Accepted: 19 November 2020

Published: 09 December 2020

Citation:

Ruiz-López MJ (2020) Mosquito Behavior and Vertebrate Microbiota

Interaction: Implications for

Pathogen Transmission.

Front. Microbiol. 11:573371.

doi: 10.3389/fmicb.2020.573371
The microbiota is increasingly recognized for its ability to influence host health and individual fitness through multiple pathways, such as nutrient synthesis, immune system development, and even behavioral processes. Most of these studies though focus on the direct effects microbiota has on its host, but they do not consider possible interactions with other individuals. However, host microbiota can change not only host behavior but also the behavior of other individuals or species toward the host. For example, microbes can have an effect on animal chemistry, influencing animal behaviors mediated by chemical communication, such as mosquito attraction. We know that host skin microbes play a major role in odor production and thus can affect the behavior of mosquitoes leading to differences in attraction to their hosts. Ultimately, the vector feeding preference of mosquitoes conditions the risk of vertebrates of coming into contact with a vector-borne pathogen, affecting its transmission, and thus epidemiology of vector-borne diseases. In this mini review, I provide an overview of the current status of research on the interaction between mosquito behavior and host skin microbiota, both in humans and other vertebrates. I consider as well the factors that influence vertebrate skin microbiota composition, such as sex, genetic makeup, and infection status, and discuss the implications for pathogen transmission.

Keywords: microbiota, chemical communication, host preference, mosquitoes, vector-borne disease, pathogen transmission

\section{INTRODUCTION}

In a world dominated by microorganisms, animals host diverse microbial communities on different body parts. These communities of symbiotic microorganisms consist of bacteria, archaea, fungi, and viruses, and are of significant importance to host health. In addition to their involvement in important host physiological processes like digestion and nutrient synthesis (Cummings and Macfarlane, 1997), they modulate immune system development (Round and Mazmanian, 2009; Bengmark, 2013) and offer protection against pathogens. This protection is achieved by limiting pathogen adhesion to host cells (Buffie and Pamer, 2013), competing for resources (Kamada et al., 2012), or producing antimicrobial compounds (Fukuda et al., 2011). Changes in composition of the microbiota can lead to physiological changes that will increase the risk of infection by opportunistic pathogens or impair the immune response (Croswell et al., 2009). 
The skin is the largest organ in the body and the first barrier of interaction with the environment. The direct effect of skin microbiota on host health has been studied both in humans (Cogen et al., 2008) and wildlife (Williams et al., 2019). For instance, susceptibility to chytridiomycosis in amphibians is associated with differences in skin microbiota composition (Bates et al., 2018). Research also shows that certain skin-associated bacteria inhibit the fungal pathogens that cause chytridiomycosis (Kueneman et al., 2016) and white nose syndrome in bats (Hoyt et al., 2015). In addition, skin microbiota generates odors that act as chemical cues to attract vectors that use olfaction as their main sense to choose their host. This is the case of mosquitoes (Rudolfs, 1922), which are known vectors of many life-threatening diseases, such as malaria, West Nile virus (WNV), or Dengue (Chen et al., 1993; Shin et al., 2002; Balenghien et al., 2008). The transmission of vector-borne diseases depends significantly on how the vector selects its feeding host (Gandon, 2018). Those individuals that are more attractive have a higher risk of coming into contact with a pathogen. Therefore, the specific odor profile of individuals and species that lead to differences in the attraction will profoundly affect the epidemiology of vector-borne diseases. The present paper provides an overview of the current status of research on the interaction between mosquito behavior and skin microbiota both in humans and other vertebrates. The focus of this mini review is mammals and birds because they are the main zoonosis reservoirs. I will discuss what we know about: (i) the role that host skin microbiota plays in odor production; (ii) how changes in skin microbiota composition can lead to differences in mosquito attraction to their hosts both at the intraspecies and interspecies level; and (iii) what factors may affect the skin microbiota composition and thus mediate disease transmission. I will identify both the knowledge gaps and potential future research lines that would help to understand the interaction between mosquito behavior and vertebrate skin microbiota and its impact on health and disease spread.

\section{THE VERTEBRATE SKIN MICROBIOTA AND VOLATILE PRODUCTION}

The microbiota of the human skin is highly complex (Grice et al., 2008), and overall microbial composition varies strongly between individuals depending on factors, such as age, sex, or habits (Fierer et al., 2008). Studies in other mammals have revealed that different species have distinct skin microbial communities, which are in general more diverse than the microbial communities in humans (Council et al., 2016; Ross et al., 2018). Some of these differences were driven by changes in the abundance of certain groups of bacteria (A decrease in Actinobacteria and an increase of Chloroflexi and Bacteroidetes; Ross et al., 2018). For some mammals, including humans, skin sites vary in their microbial composition and skin microorganisms tend to be more abundant around glands and skin pouches (Verhulst et al., 2010a; Leclaire et al., 2014; Kamus et al., 2018).
Studies in birds show that like mammal skin, feathers harbor their own microbial community with a composition that varies between individuals and species (Engel et al., 2018). Staphilococcus, Bacillus, Pseudomonas, and Stenotrophomona are some of the most common bacteria genera found on the plumage of different bird species (Whittaker et al., 2019). Birds' main holocrine gland is the uropygial gland, which produces an oily secretion that birds preen onto their feathers. A significant amount of this secretion is formed by lipids that may control the growth of feather-degrading bacteria living on the plumage or be used as nutrients by feather microbiota that produce body odors (Purton, 1986). In addition, it has been shown in several species that uropygial gland area and secretion produced also contain bacteria (Martín-Vivaldi et al., 2010; Whittaker et al., 2019).

Symbiotic microbial communities in the skin of both mammals and birds play a significant role in odor production through the generation of volatile compounds like linear alcohols, methyl ketones, and carboxylic acids (Madigan et al., 2010). Different species of skin bacteria have distinct metabolic routes that produce a variety of compounds. For example, in humans, the odor associated with the axillary glands has been linked to Corynebacteria (Leyden et al., 1981), which generate volatile fatty acids (James et al., 2004). Staphylococcus species, common in humans and birds, can metabolize branched-chain amino acids into short-chain amino acids that are volatile and highly odorous (James et al., 2004). In birds, volatile compounds from the uropygial gland secretion were linked with several bacteria genera, including Pseudomonas and Staphylococcus (Whittaker et al., 2019). Therefore, skin/ feather microbiota that differs not only in composition but also in the abundance of certain bacteria species will generate a characteristic odor profile for each individual (Theis et al., 2012; Leclaire et al., 2014). These olfactory cues are associated with host sex, age, and social interactions, indicating the potential for chemical communication (Fierer et al., 2008; Theis et al., 2012; Leclaire et al., 2014).

\section{MOSQUITO BEHAVIORAL RESPONSE TO SKIN MICROBIOTA VOLATILES IN VERTEBRATES}

The idea that the volatile compounds produced by skin microbiota could attract mosquitoes was first proposed by Schreck and James (1968). They tested whether the volatiles of a broth where they had grown bacteria (Bacillus cereus) was attractive to Aedes aegypti. The results showed that the volatiles produced were attractive. Since then, several studies have shown that human skin bacteria produce volatiles that are attractive to mosquitoes (De Jong and Knols, 1995; Braks et al., 2000; Verhulst et al., 2009). These studies confirm that skin microbiota influences host seeking behavior in mosquitoes. But skin microbiota composition is unique for each individual, contributing to the generation of distinct odor profiles, which drive mosquito host seeking behavior and selection (Verhulst et al., 2018; Figure 1). In fact, it is 


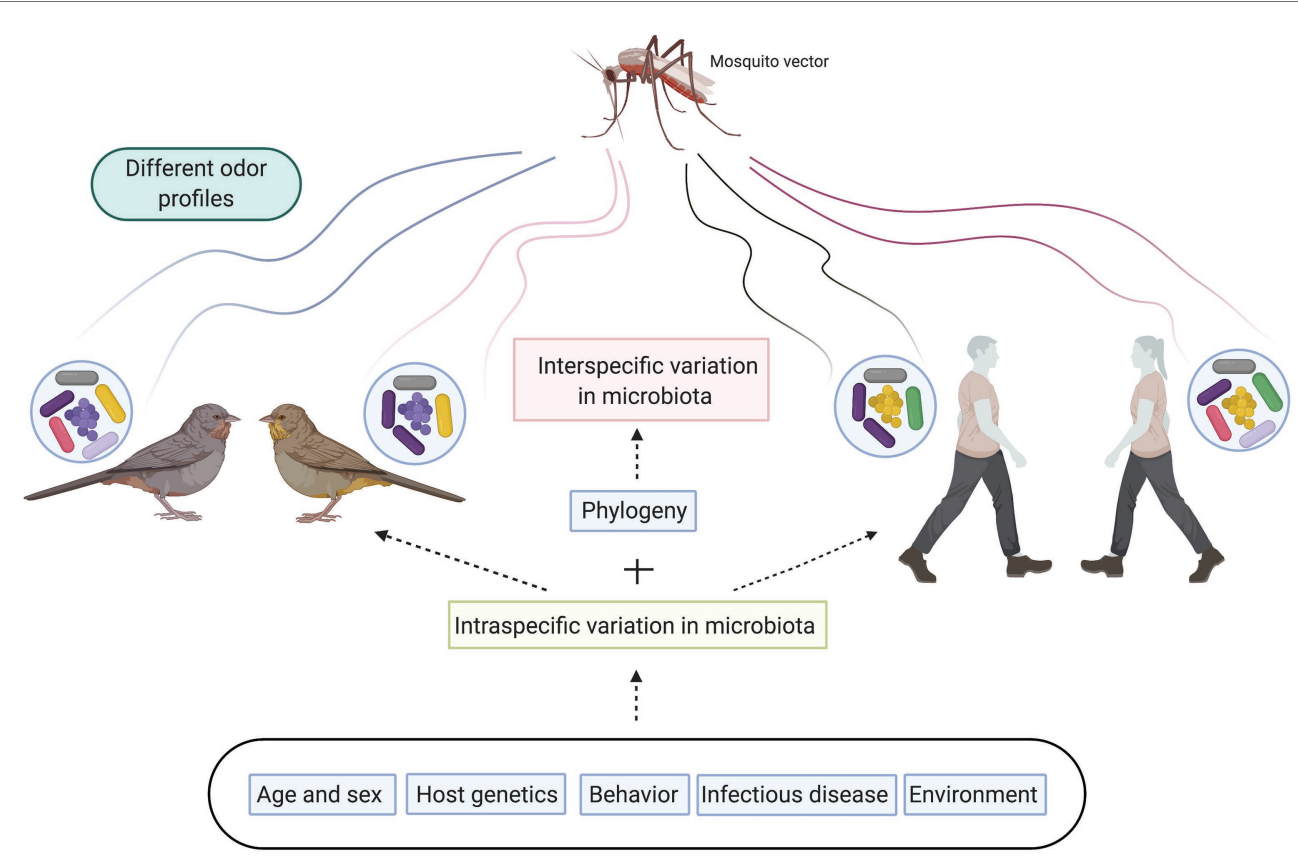

FIGURE 1 | Graphical outline of factors affecting skin and plumage microbiota composition leading to intraspecific and interspecific differences in microbiota profiles. These different microbiota profiles will produce distinct odor profiles that mosquitos use as cue to select host they will feed on.

clear that mosquitoes show a preference to bite certain individuals, demonstrating that there are intraspecific differences in the attractiveness of individuals to mosquitoes (see Bernier et al., 2002 and Mukabana et al., 2002 for examples in humans). Several studies in humans have shown that these differences in attractiveness are mediated by the microbiota. Two species of bacteria were identified as key in determining attractiveness, Pseudomonas aeruginosa, and Staphilococcus epidermis. Mosquito species of the Anopheles gambiae complex were not attracted to the odor produced by $P$. aeruginosa, while the odor of $S$. epidermis was attractive (Verhulst et al., 2010b, 2011). In addition, Verhulst et al. (2011) demonstrated that the more attractive individuals had less diverse microbiota, but hosted a higher abundance of some bacteria including Staphylococcus. In contrast, Pseudomonas was more abundant in poorly attractive individuals. This pattern of intraspecific differences in attractiveness to mosquitoes plays a significant role in pathogen exposure and pathogen transmission dynamics. The more attractive individuals have more likelihood of being bitten, increasing their chances of being infected by mosquito-borne pathogens and driving pathogen transmission.

Although most studies linking bacteria, volatile production and mosquito attraction have been carried out in humans and anthropophilic mosquitoes, studies in other species show similar patterns. For example, in some species of birds, both the uropygial gland secretion and volatile compounds of skin and plumage have been shown to attract mosquitoes (Russell and Hunter, 2005; Bernier et al., 2008; but see Douglas et al., 2005). However, despite the evidence that bacteria in the uropygial gland and plumage produce volatile compounds that can be used in olfactory communication (Maraci et al., 2018), there is no study yet linking the production of volatile compounds that specifically attract mosquitos with bacteria species in birds.

Mosquito species differ widely in their host preference, defined as "the trait to preferentially select certain host species above others" (Takken and Verhulst, 2013). While many mosquito species are opportunistic and their host preference is mainly driven by host abundance and availability, other species show strong preferences, feeding mainly on mammals (mammophilic), birds (ornithophilic), or other vertebrate groups such as reptiles (Chaves et al., 2010; Martínez-de la Puente et al., 2015). Some mosquito species even exhibit a marked preference to feed on a single host species, no matter the circumstances, like An. gambiae sensu stricto that is highly anthropophilic (Pates, 2002). Host preference is one of the key determinants of the vectorial competence for disease transmission because it determines the risk that a vertebrate species will come into contact with a pathogen (Gandon, 2018). Those species of mosquitoes with plastic behavior that adapt to feed on available vertebrate species play a key role in pathogen transmission between species and may drive zoonosis emergence (Takken and Verhulst, 2013; Yakob et al., 2018). One of the classic examples illustrating this situation is the transmission of WNV to humans. This virus is maintained in nature in an enzootic cycle involving ornithophilic mosquitoes, which are the transmission vector. Culex pipiens is one of the primary vectors of WNV and typically feeds on birds. However, under certain circumstances like migration events when the abundance of birds changes, they switch host to humans contributing to the spread of WNV in humans (Farajollahi et al., 2011). To further understand host selection in mosquitoes that act as vectors of WNV, Spanoudis et al. (2020) compared 
the responses of Culex quinquefasciatus and Cx.pipiens molestus to volatiles of different bird species. Culex quinquefasciatus shows phenotypic plasticity and its feeding preference varies in different ecotypes (Mboera and Takken, 1999; Molaei etal., 2006). Culex pipiens molestus is an anthropophilic form of Cx. pipiens (Vinogradova, 2000) adapted to urban environments. Both species of mosquitoes responded to bird volatiles but differed in their preference (Spanoudis et al., 2020). Culex quinquefasciatus responded to the volatiles of both sexes of chickens (Gallus Gallus domesticus), and female pigeons (Columba livia). Culex pipiens molestus responded to the volatiles of chickens and magpies (Pica pica). These differences in feeding preference are critical for disease transmission. Out of the species included in the study, magpies are the most susceptible to WNV (Jiménez de Oya et al., 2018) allowing its circulation in wild populations (Napp et al., 2019). Mosquitoes that prefer feeding on both magpies and humans facilitate transmission of WNV between the bird reservoir and humans. This example shows that to determine the potential of mosquitoes as disease vectors it is crucial to understand their feeding preferences, which involves studying how mosquitoes select their host, and how odor profiles and microbiota are influencing this choice. In this sense, several studies in different taxa have analyzed if the odor of different species was equally attractive to a set of species of mosquitoes. Bakker et al. (2020) set traps with odors from chimpanzees (Pan troglodytes), humans, and cows (Bos taurus) and identified the mosquitoes captured. Most of the mosquito species trapped during this study were equally attracted to all mammal species tested showing a generalistic host preference. Another study carried out with house sparrows (Passer domesticus) showed no differences in the response of the ornitophilic mosquitoes ( $C x$. pipiens) and mammophilic mosquitoes [Aedes (Ochlerotatus) caspius] when exposed to the uropygial gland secretions (DíezFernández et al., 2020a). Therefore, it seems that the preference of ornithophilic mosquitoes for avian hosts is not associated with attraction to the uropygial gland secretion odor. However, it is possible that mosquitoes respond to specific volatile compound released when the secretion is deposited on the feathers and metabolized by the bacterial community (DíezFernández et al., 2020a). In humans, it has been shown that this variation in mosquito response is in fact mediated by the composition of skin microbiota volatiles (Busula et al., 2017). In this study, two species of mosquitoes with different host preferences (An. gambiae and An. arabiensis), exhibited a different response to the volatiles released from skin bacteria from three different mammal species (human, cow, and chicken). Anopheles gambiae showed higher attraction to bacteria volatiles of human origin, and displayed a specialized response to four species of bacteria preferring volatiles from Corinebacterium minutissimum, one of the most abundant microbes in human skin. In contrast, An. arabiensis showed more attraction to bacterial volatiles from chickens responding equally to all species of bacteria tested. More studies like this one, including different vertebrate and mosquito species, will help to understand how skin microbiota drives interspecies differences in mosquito attraction and mediates potential pathogen transmission.

\section{FACTORS AFFECTING SKIN MICROBIOTA COMPOSITION: POTENTIAL IMPACT ON MOSQUITO ATTRACTION AND PATHOGEN TRANSMISSION}

Skin microbiota composition is influenced by multiple factors. In addition to the phylogeny of the host discussed above, age, sex, behavior, genetic makeup of the host, and environmental variables, also impact skin microbiota composition (Fierer et al., 2008; Theis et al., 2012; Leclaire et al., 2014; Figure 1). Therefore, these factors will indirectly affect how mosquitoes select their host leading to differential exposure to vector-borne pathogens among individuals. Some studies have analyzed the effect of sex on attractiveness to mosquitoes. One study found no differences in exposure from males and females of great tit nestlings (Parus major) to bites of Cx. pipiens (Cozzarolo et al., 2019). In contrast, Spanoudis et al. (2020) showed that female pigeons were attractive to $C x$. quinquefasciatus while males were not attractive. Regarding genetic makeup, it is recognized that there is a genetic component determining susceptibility to being bitten (Fernández-Grandon et al., 2015) and odor profile is partially genetically based (Kuhn and Natsch, 2009). Interestingly, the genes of the major histocompatibility complex (MHC), the most important cluster of immune genes, are also some of the most important candidate genes for explaining body odor (Penn and Potts, 1998) and have been linked in humans with differences in mosquito attraction (Verhulst et al., 2013). Two combined hypotheses explain the potential effect of MHC on odor. First, it has been proposed that degraded MHC molecules directly influence odor (Pearse-Pratt et al., 1992). Second, it is known that MHC variation correlates with gut microbiota composition and diversity (Bolnick et al., 2014), and that skin microbiota triggers immune responses associated with the MHC (Dillon et al., 2000). Furthermore, in two seabird species, there is an association between MHC genotypes and microbiota composition in the uropygial gland (Pearce et al., 2017) and plumage (Leclaire et al., 2019). Thus, MHC genes may also influence the odor of individuals by shaping the microbiota composition of skin/ feathers and adjacent glands, leading to differences in exposure to vector-borne pathogens among individuals.

A factor that can impact microbiota composition and has not been studied so far is infectious disease. It is known that mosquito-borne pathogens, like malaria (Taniguchi et al., 2015), are associated with changes in gut microbiota. Little is known however, about potential changes in skin microbiota. But changes in skin microbiota composition might be critical in determining disease transmission, if the new profiles make the infected individuals more attractive to mosquitoes. Although so far there are no studies associating changes in skin microbiota due to infection with attractiveness to mosquitoes, research in several vertebrate species shows that individuals infected with Plasmodium spp. are more attractive to mosquitoes [rodents (Ferguson and Read, 2004; De Moraes et al., 2014), canaries (Serinus canaria; Cornet et al., 2013a,b), house sparrows (Díez-Fernández et al., 2020b), and humans (Lacroix et al., 2005; Batista et al., 2014; Robinson et al., 2018)]. These studies show that pathogen infection, 
in this case malaria, can change an individual's odor profile, making the infected individuals more attractive to mosquitoes. If infected individuals are then more frequently bitten, this would enhance the transmission of the pathogen in the population. Although all of these studies identify odor profiles, it seems reasonable to think that potential changes in skin microbiota composition may play a substantial role and it should be studied if the skin and plumage microbiota also change during different infections caused by mosquito-borne pathogens.

\section{CONCLUSION AND FUTURE DIRECTIONS}

Vector-borne pathogens are the causative agents of some of the most harmful diseases in humans, like malaria, dengue, and yellow fever. In addition, they are also the cause of enormous economic losses in domestic animals and population declines among wildlife. Understanding how vectors select their feeding host is critical to understand parasite transmission. For some vectors, like mosquitoes, odor is the main cue to select their hosts. Multiple studies confirm that the microbiota on skin and plumage plays a critical role in body odor production. Therefore, the differences in attractiveness of individuals and species to mosquitoes may be explained by variation in the microbiota composition. However, most of these studies are associative and do not demonstrate causal relationships. One of the challenges is linking bacteria species with volatiles and odor production that will cause differences in the attractiveness to mosquitoes. To bridge this gap, a potential avenue would be to stablish gnotobiotic animal models colonized by known microbes. These animal models in combination with the use of "omic" tools, like metatranscriptomics and metabolomics, will help to link bacteria species with metabolic pathways that are responsible for the volatile by-products. In addition, to further comprehend the mechanisms underlying the interaction between mosquito behavior and host microbiota, more studies including different species of vertebrates and mosquitoes are necessary. This will help to understand which are the cues generalists and specialized

\section{REFERENCES}

Bakker, J. W., Loy, D. E., Takken, W., Hahn, B. H., and Verhulst, N. O. (2020). Attraction of mosquitoes to primate odours and implications for zoonotic Plasmodium transmission. Med. Vet. Entomol. 34, 17-26. doi: 10.1111/ mve. 12402

Balenghien, T., Vazeille, M., Grandadam, M., Schaffner, F., Zeller, H., Reiter, P., et al. (2008). Vector competence of some French Culex and Aedes mosquitoes for West Nile virus. Vector Borne Zoonotic Dis. 8, 589-595. doi: 10.1089/ vbz.2007.0266

Bates, K. A., Clare, F. C., O’Hanlon, S., Bosch, J., Brookes, L., Hopkins, K., et al. (2018). Amphibian chytridiomycosis outbreak dynamics are linked with host skin bacterial community structure. Nat. Commun. 9:693. doi: 10.1038/s41467-018-02967-w

Batista, E. P., Costa, E. F., and Silva, A. A. (2014). Anopheles darlingi (Diptera: Culicidae) displays increased attractiveness to infected individuals with Plasmodium vivax gametocytes. Parasit. Vectors 7:251. doi: 10.1186/1756-3305-7-251

Bengmark, S. (2013). Gut microbiota, immune development and function. Pharmacol. Res. 69, 87-113. doi: 10.1016/j.phrs.2012.09.002 mosquitoes are responding to and what are the common patterns of host-seeking behavior. For example, mosquitoes with different host feeding preferences may be responding to different odor profiles generated by different microbiota composition or specific bacteria. In contrast, mosquitoes with a generalist feeding preference might be responding to common odor profiles across species generated by bacteria that are found across different host species. It will also be important to gain a better understanding of how the factors that affect microbiota affect host selection by mosquitoes. Some examples of what can be done include looking at the genetic basis of skin microbiota composition (Davenport, 2016) using genome wide association studies, or linking infectious disease caused by mosquito-borne pathogens with changes in skin microbiota that can lead to differences in attractiveness to mosquitoes. Overall, future research should include a combination of laboratory and ecological studies on the interaction between skin microbiota and host seeking behavior of mosquitoes that will help to reveal some of the most important factors underlying pathogen amplification and transmission.

\section{AUTHOR CONTRIBUTIONS}

MR-L designed the mini review and wrote the manuscript.

\section{FUNDING}

MR-L was supported by a Marie Sklodowska-Curie Fellowship from the European Commission (grant number 795537, “TRANSWNV”).

\section{ACKNOWLEDGMENTS}

I would like to thank Alazne Díez-Fernández and Jordi Figuerola for the interesting discussions and critical input that they have provided making this review possible. Figure 1 was created using BioRender.com.

Bernier, U. R., Allan, S. A., Quinn, B. P., Kline, D. L., Barnard, D. R., and Clark, G. G. (2008). Volatile compounds from the integument of white Leghorn chickens (Gallus Gallus domesticus L.): candidate attractants of ornithophilic mosquito species. J. Sep. Sci. 31, 1092-1099. doi: 10.1002/jssc.200700434

Bernier, U. R., Kline, D. L., Schreck, C. E., Yost, R. A., and Barnard, D. R. (2002). Chemical analysis of human skin emanations: comparison of volatiles from humans that differ in attraction of Aedes aegypti (Diptera: Culicidae). J. Am. Mosq. Control Assoc. 18, 186-195.

Bolnick, D. I., Snowberg, L. K., Caporaso, J. G., Lauber, C., Knight, R., and Stutz, W. E. (2014). Major histocompatibility complex class IIb polymorphism influences gut microbiota composition and diversity. Mol. Ecol. 23, 4831-4845. doi: $10.1111 / \mathrm{mec} .12846$

Braks, M. A., Scholte, E. J., Takken, W., and Dekker, T. (2000). Microbial growth enhances the attractiveness of human sweat for the malaria mosquito, Anopheles gambiae sensu stricto (Diptera: Culicidae). Chemoecology 10, 129-134. doi: 10.1007/PL00001814

Buffie, C. G., and Pamer, E. G. (2013). Microbiota-mediated colonization resistance against intestinal pathogens. Nat. Rev. Immunol. 13, 790-801. doi: $10.1038 /$ nri3535 
Busula, A. O., Takken, W., De Boer, J. G., Mukabana, W. R., and Verhulst, N. O. (2017). Variation in host preferences of malaria mosquitoes is mediated by skin bacterial volatiles. Med. Vet. Entomol. 31, 320-326. doi: 10.1111/mve. 12242

Chaves, L. F., Harrington, L. C., Keogh, C. L., Nguyen, A. M., and Kitron, U. D. (2010). Blood feeding patterns of mosquitoes: random or structured? Front. Zool. 7:3. doi: 10.1186/1742-9994-7-3

Chen, W. J., Wei, H. L., Hsu, E. L., and Chen, E. R. (1993). Vector competence of Aedes albopictus and Ae. aegypti (Diptera: Culicidae) to dengue 1 virus on Taiwan: development of the virus in orally and parenterally infected mosquitoes. J. Med. Entomol. 30, 524-530. doi: 10.1093/jmedent/30.3.524

Cogen, A. L., Nizet, V., and Gallo, R. L. (2008). Skin microbiota: a source of disease or defence? Br. J. Dermatol. 158, 442-455. doi: 10.1111/j.13652133.2008.08437.x

Cornet, S., Nicot, A., Rivero, A., and Gandon, S. (2013a). Malaria infection increases bird attractiveness to uninfected mosquitoes. Ecol. Lett. 16, 323-329. doi: 10.1111/ele.12041

Cornet, S., Nicot, A., Rivero, A., and Gandon, S. (2013b). Both infected and uninfected mosquitoes are attracted toward malaria infected birds. Malar. J. 12:179. doi: $10.1186 / 1475-2875-12-179$

Council, S. E., Savage, A. M., Urban, J. M., Ehlers, M. E., Skene, J. P., Platt, M. L., et al. (2016). Diversity and evolution of the primate skin microbiome. Proc. Biol. Sci. 283:20152586. doi: 10.1098/rspb.2015.2586

Cozzarolo, C. S., Sironi, N., Glaizot, O., Pigeault, R., and Christe, P. (2019). Sex-biased parasitism in vector-borne disease: vector preference? PLoS One 14:e0216360. doi: 10.1371/journal.pone.0216360

Croswell, A., Amir, E., Teggatz, P., Barman, M., and Salzman, N. H. (2009). Prolonged impact of antibiotics on intestinal microbial ecology and susceptibility to enteric Salmonella infection. Infect. Immun. 77, 2741-2753. doi: 10.1128/ IAI.00006-09

Cummings, J. H., and Macfarlane, G. T. (1997). Role of intestinal bacteria in nutrient metabolism. JPEN J. Parenter. Enteral Nutr. 21, 357-365. doi: $10.1177 / 0148607197021006357$

Davenport, E. R. (2016). Elucidating the role of the host genome in shaping microbiome composition. Gut Microbes 7, 178-184. doi: 10.1080/19490976. 2016.1155022

De Jong, R., and Knols, B. G. (1995). Selection of biting sites on man by two malaria mosquito species. Experientia 51, 80-84. doi: 10.1007/BF01964925

De Moraes, C. M., Stanczyk, N. M., Betz, H. S., Pulido, H., Sim, D. G., Read, A. F., et al. (2014). Malaria-induced changes in host odors enhance mosquito attraction. Proc. Natl. Acad. Sci. U. S. A. 111, 11079-11084. doi: 10.1073/pnas.1405617111

Díez-Fernández, A., Martínez-de la Puente, J., Gangoso, L., Ferraguti, M., Soriguer, R., and Figuerola, J. (2020a). House sparrow uropygial gland secretions do not attract ornithophilic nor mammophilic mosquitoes. Med. Vet. Entomol. 34, 225-228. doi: 10.1111/mve.12401

Díez-Fernández, A., Martínez-de la Puente, J., Gangoso, L., López, P., Soriguer, R., Martín, J., et al. (2020b). Mosquitoes are attracted by the odour of Plasmodiuminfected birds. Int. J. Parasitol. 50, 569-575. doi: 10.1016/j.ijpara.2020. 03.013

Dillon, R. J., Vennard, C. T., and Charnley, A. K. (2000). Exploitation of gut bacteria in the locust. Nature 403:851. doi: 10.1038/35002669

Douglas, H. D. 3rd, Co, J. E., Jones, T. H., Conner, W. E., and Day, J. F. (2005). Chemical odorant of colonial seabird repels mosquitoes. J. Med. Entomol. 42, 647-651. doi: 10.1093/jmedent/42.4.647

Engel, K., Sauer, J., Jünemann, S., Winkler, A., Wibberg, D., Kalinowski, J., et al. (2018). Individual- and species-specific skin microbiomes in three different estrildid finch species revealed by $16 \mathrm{~S}$ amplicon sequencing. Microb. Ecol. 76, 518-529. doi: 10.1007/s00248-017-1130-8

Farajollahi, A., Fonseca, D. M., Kramer, L. D., and Marm Kilpatrick, A. (2011). "bird biting" mosquitoes and human disease: a review of the role of Culex pipiens complex mosquitoes in epidemiology. Infect. Genet. Evol. 11, 1577-1585. doi: 10.1016/j.meegid.2011.08.013

Ferguson, H. M., and Read, A. F. (2004). Mosquito appetite for blood is stimulated by Plasmodium chabaudi infections in themselves and their vertebrate hosts. Malar. J. 3:12. doi: 10.1186/1475-2875-3-12

Fernández-Grandon, G. M., Gezan, S. A., Armour, J. A., Pickett, J. A., and Logan, J. G. (2015). Heritability of attractiveness to mosquitoes. PLoS One 10:e0122716. doi: 10.1371/journal.pone.0122716
Fierer, N., Hamady, M., Lauber, C. L., and Knight, R. (2008). The influence of sex, handedness, and washing on the diversity of hand surface bacteria. Proc. Natl. Acad. Sci. U. S. A. 105, 17994-17999. doi: 10.1073/pnas.08079 20105

Fukuda, S., Toh, H., Hase, K., Oshima, K., Nakanishi, Y., Youshimura, K., et al. (2011). Bifidobacteria can protect from enteropathogenic infection through production of acetate. Nature 469, 543-547. doi: 10.1038/nature09646

Gandon, S. (2018). Evolution and manipulation of vector host choice. Am. Nat. 192, 23-34. doi: $10.1086 / 697575$

Grice, E. A., Kong, H. H., Renaud, G., Young, A. C., Bouffard, G. G., Blakesley, R. W., et al. (2008). A diversity profile of the human skin microbiota. Genome Res. 18, 1043-1050. doi: 10.1101/gr.075549.107

Hoyt, J. R., Cheng, T. L., Langwig, K. E., Hee, M. M., Frick, W. F., and Kilpatrick, A. M. (2015). Bacteria isolated from bats inhibit the growth of Pseudogymnoascus destructans, the causative agent of white-nose syndrome. PLoS One 10:e0121329. doi: 10.1371/journal.pone.0121329

James, A. G., Hyliands, D., and Johnston, H. (2004). Generation of volatile fatty acids by axillary bacteria. Int. J. Cosmet. Sci. 26, 149-156. doi: 10.1111/j. 1467-2494.2004.00214.x

Jiménez de Oya, N., Camacho, M. C., Blázquez, A. B., Lima-Barbero, J. F., Saiz, J. C., Höfle, U., et al. (2018). High susceptibility of magpie (Pica pica) to experimental infection with lineage 1 and 2 West Nile virus. PLoS Negl. Trop. Dis. 12:e0006394. doi: 10.1371/journal.pntd.0006394

Kamada, N., Kim, Y. G., Sham, H. P., Vallance, B. A., Puente, J. L., Martens, E. C., et al. (2012). Regulated virulence controls the ability of a pathogen to compete with the gut microbiota. Science 336, 1325-1329. doi: 10.1126/ science. 1222195

Kamus, L. J., Theoret, C., and Costa, M. C. (2018). Use of net generation sequencing to investigate the microbiota of experimentally induced wounds and the effect of bandaging in horses. PLoS One 13:e0206989. doi: 10.1371/ journal.pone.0206989

Kueneman, J. G., Woodhams, D. C., Harris, R., Archer, H. M., Knight, R., and McKenzie, V. J. (2016). Probiotic treatment restores protection against lethal fungal infection lost during amphibian captivity. Proc. Biol. Sci. 283:20161553. doi: 10.1098/rspb.2016.1553

Kuhn, F., and Natsch, A. (2009). Body odour of monozygotic human twins: a common pattern of odorant carboxylic acids released by a bacterial aminoacylase from axilla secretions contributing to an inherited body odour type. J. R. Soc. Interface 6, 377-392. doi: 10.1098/rsif.2008.0223

Lacroix, R., Mukabana, W. R., Gouagna, L. C., and Koella, J. C. (2005). Malaria infection increases attractiveness of humans to mosquitoes. PLoS Biol. 3:e298. doi: 10.1371 /journal.pbio.0030298

Leclaire, S., Nielsen, J. F., and Drea, C. M. (2014). Bacterial communities in meerkat anal scent secretions vary with host sex, age, and group membership. Behav. Ecol. 25, 996-1004. doi: 10.1093/beheco/aru074

Leclaire, S., Strandh, M., Dell'Ariccia, G., Gabirot, M., Westerdahl, H., and Bonadonna, F. (2019). Plumage microbiota covaries with the major histocompatibility complex in blue petrels. Mol. Ecol. 28, 833-846. doi: 10.1111/mec.14993

Leyden, J. J., McGinley, K. J., Hölzle, E., Labows, J. N., and Kligman, A. M. (1981). The microbiology of the human axilla and its relationship to axillary odor. J. Invest. Dermatol. 77, 413-416. doi: 10.1111/1523-1747.ep12494624

Madigan, M. T., Martinko, J. M., Stahl, D. A., and Clark, D. P. (2010). Brock biology of microorganisms. San Francisco: Benjamin Cummings.

Maraci, Ö., Engel, K., and Caspers, B. A. (2018). Olfactory communication via microbiota: what is known in birds? Gene 9:387. doi: 10.3390/genes9080387

Martínez-de la Puente, J., Muñoz, J., Capelli, G., Montarsi, F., Soriguer, R., Arnoldi, D., et al. (2015). Avian malaria parasites in the last supper: identifying encounters between parasites and the invasive Asian mosquito tiger and native mosquito species in Italy. Malar. J. 14:32. doi: 10.1186/s12936-015-0571-0

Martín-Vivaldi, M., Peña, A., Peralta-Sánchez, J. M., Sánchez, L., Ananou, S. Ruiz-Rodríguez, M., et al. (2010). Antimicrobial chemicals in hoopoe preen secretions are produced by symbiotic bacteria. Proc. Biol. Sci. 277, 123-130. doi: $10.1098 /$ rspb.2009.1377

Mboera, L. E. G., and Takken, W. (1999). Odour-mediated host preference of Culex quinquefasciatus in Tanzania. Entomol. Exp. Appl. 92, 83-88. doi: 10.1046/j.1570-7458.1999.00527.x

Molaei, G., Andreadis, T. G., Armstrong, P. M., Anderson, J. F., and Vossbrinck, C. R. (2006). Host feeding patterns of Culex mosquitoes and West 
Nile virus transmission, northeastern United States. Emerg. Infect. Dis. 12, 468-474. doi: 10.3201/eid1203.051004

Mukabana, W. R., Takken, W., Coe, R., and Knols, B. G. (2002). Host-specific cues cause differential attractiveness of Kenyan men to the African malaria vector Anopheles gambiae. Malar. J. 1:17. doi: 10.1186/1475-2875-1-17

Napp, S., Montalvo, T., Piñol-Baena, C., Gómez-Martín, M. B., NicolásFrancisco, O., Soler, M., et al. (2019). Usefulness of Eurasian magpies (Pica pica) for West Nile virus surveillance in non-endemic and endemic situations. Viruses 11:716. doi: 10.3390/v11080716

Pates, H. V. (2002). Zoophilic and anthropophilic behaviour in the Anopheles gambiae complex. PhD thesis. London School of Hygiene \& Tropical Medicine.

Pearce, D. S., Hoover, B. A., Jennings, S., Nevitt, G. A., and Docherty, K. M. (2017). Morphological and genetic factors shape the microbiome of a seabird species (Oceanodroma leucorhoa) more than environmental and social factors. Microbiome 5:146. doi: 10.1186/s40168-017-0365-4

Pearse-Pratt, R., Schellinck, H., Brown, R., and Roser, B. (1992). "Evolutionary and immunological implications of the role of the MHC in olfactory signalling" in Chemical signals in vertebrates 6. eds. R. L. Doty and D. Müller-Schwarze (Boston, MA: Springer), 167-173.

Penn, D., and Potts, W. K. (1998). Untrained mice discriminate MHC-determined odors. Physiol. Behav. 64, 235-243. doi: 10.1016/S0031-9384(98)00052-3

Purton, M. D. (1986). Skin surface topography in the domestic fowl and Japanese quail. Br. Vet. J. 142, 446-452. doi: 10.1016/0007-1935(86)90046-1

Robinson, A., Busula, A. O., Voets, M. A., Beshir, K. B., Caulfield, J. C., and Powers, S. J. (2018). Plasmodium-associated changes in human odor attract mosquitoes. Proc. Natl. Acad. Sci. U. S. A. 115, E4209-E4218. doi: 10.1073/ pnas. 1721610115

Ross, A. A., Müller, K. M., Weese, J. S., and Neufeld, J. D. (2018). Comprehensive skin microbiome analysis reveals the uniqueness of human skin and evidence for phylosymbiosis within the class Mammalia. Proc. Natl. Acad. Sci. U. S. A. 115, E5786-E5795. doi: 10.1073/pnas. 1801302115

Round, J. L., and Mazmanian, S. K. (2009). The gut microbiota shapes intestinal immune responses during health and disease. Nat. Rev. Immunol. 9, 313-323. doi: $10.1038 /$ nri2515

Rudolfs, W. (1922). Chemotropism in mosquitoes. Bull. N.J. Agric. Exp. Stn. $367,4-23$.

Russell, C. B., and Hunter, F. F. (2005). Attraction of Culex pipiens/restuans (Diptera: Culicidae) mosquitoes to bird uropygial gland odors at two elevations in the Niagara region of Ontario. J. Med. Entomol. 42, 301-305. doi: 10.1603/0022-2585(2005)042[0301:AOCRDC]2.0.CO;2

Schreck, C. E., and James, J. (1968). Broth cultures of bacteria that attract female mosquitoes. Mosq. News 28, 33-38.

Shin, E. H., Kim, T. S., Lee, H. W., Lee, J. S., and Lee, W. J. (2002). Vector competence of Anopheles lesteri Baisas and $\mathrm{Hu}$ (Diptera: Culicidae) to Plasmodium vivax in Korea. Korean J. Parasitol. 40, 41-44. doi: 10.3347/ kjp.2002.40.1.41

Spanoudis, C. G., Andreadis, S. S., Bray, D. P., Savopoulou-Soultani, M., and Ignell, R. (2020). Behavioural response of the house mosquitoes Culex quinquefasciatus and Culex pipiens molestus to avian odours and its reliance on carbon dioxide. Med. Vet. Entomol. 34, 129-137. doi: 10.1111/mve.12429

Takken, W., and Verhulst, N. O. (2013). Host preferences of blood-feeding mosquitoes. Annu. Rev. Entomol. 58, 433-453. doi: 10.1146/annurevento-120811-153618
Taniguchi, T., Miyauchi, E., Nakamura, S., Hirai, M., Suzue, K., Imai, T., et al. (2015). Plasmodium berghei ANKA causes intestinal malaria associated with dysbiosis. Sci. Rep. 5:15699. doi: 10.1038/srep15699

Theis, K. R., Schmidt, T. M., and Holekamp, K. E. (2012). Evidence for a bacterial mechanism for group-specific social odors among hyenas. Sci. Rep. 2:615. doi: $10.1038 /$ srep00615

Verhulst, N. O., Andriessen, R., Groenhagen, U., Bukovinszkiné Kiss, G., Schulz, S., Takken, W., et al. (2010b). Differential attraction of malaria mosquitoes to volatile blends produced by human skin bacteria. PLoS One 5:e15829. doi: 10.1371/journal.pone.0015829

Verhulst, N. O., Beijleveld, H., Knols, B. G., Takken, W., Schraa, G., Bouwmeester, H. J., et al. (2009). Cultured skin microbiota attracts malaria mosquitoes. Malar. J. 8:302. doi: 10.1186/1475-2875-8-302

Verhulst, N. O., Beijleveld, H., Qiu, Y. T., Maliepaard, C., Verduyn, W., Haasnoot, G. W., et al. (2013). Relation between HLA genes, human skin volatiles and attractiveness of humans to malaria mosquitoes. Infect. Genet. Evol. 18, 87-93. doi: 10.1016/j.meegid.2013.05.009

Verhulst, N. O., Boulanger, N., and Spitzen, J. (2018). "Impact of skin microbiome on attractiveness to arthropod vectors and pathogen transmission" in Skin and arthropod vectors. ed. N. Boulanger (Strasbourg, France: Academic Press), 55-81.

Verhulst, N. O., Qiu, Y. T., Beijleveld, H., Maliepaard, C., Knights, D., Schulz, S., et al. (2011). Composition of human skin microbiota affects attractiveness to malaria mosquitoes. PLoS One 6:e28991. doi: 10.1371/journal.pone.0028991

Verhulst, N. O., Takken, W., Dicke, M., Schraa, G., and Smallegange, R. C. (2010a). Chemical ecology of interactions between human skin microbiota and mosquitoes. FEMS Microbiol. Ecol. 74, 1-9. doi: 10.1111/j.1574-6941.2010.00908.x

Vinogradova, E. B. (2000). Culex pipiens mosquitoes: Taxonomy, distribution, ecology, phisiology, genetis, applied importance and control. 1st Edn. Sofia: Pensoft Publishers.

Whittaker, D. J., Slowinski, S. P., Greenberg, J. M., Alian, O., Winters, A. D., Ahmad, M. M., et al. (2019). Experimental evidence that symbiotic bacteria produce chemical cues in a songbird. J. Exp. Biol. 222:jeb202978. doi: 10.1242/ jeb.202978

Williams, C. L., Caraballo-Rodríguez, A. M., Allaband, C., Zarrinpar, A., Knight, R., and Gauglitz, J. M. (2019). Wildlife-microbiome interactions and disease: exploring opportunities for disease mitigation across ecological scales. Drug Discov. Today Dis. Model. 28, 105-115. doi: 10.1016/j.ddmod.2019.08.012

Yakob, L., Lloyd, A. L., Kao, R. R., Ferguson, H. M., Brock, P. M., Drakeley, C., et al. (2018). Plasmodium knowlesi invasion following spread by infected mosquitoes, macaques and humans. Parasitology 145, 101-110. doi: 10.1017/ S0031182016002456

Conflict of Interest: The author declares that the research was conducted in the absence of any commercial or financial relationships that could be construed as a potential conflict of interest.

Copyright (๑ 2020 Ruiz-López. This is an open-access article distributed under the terms of the Creative Commons Attribution License (CC BY). The use, distribution or reproduction in other forums is permitted, provided the original author(s) and the copyright owner(s) are credited and that the original publication in this journal is cited, in accordance with accepted academic practice. No use, distribution or reproduction is permitted which does not comply with these terms. 